\title{
Aplaminal: A Novel Cytotoxic Aminal Isolated from the Sea Hare Aplysia kurodai
}

Takeshi Kuroda and Hideo Kigoshi*

Department of Chemistry, University of Tsukuba, 1-1-1 Tennoudai, Tsukuba, Ibaraki 305-8571, Japan

List of Supporting Information

Experimental Procedures

${ }^{1} \mathrm{H}$ NMR Data for aplaminal (1; $270 \mathrm{MHz}$, acetone- $d_{6}$ )

Chart 1. ${ }^{1} \mathrm{H}$ NMR Spectrum of aplaminal (1; $\left.270 \mathrm{MHz}, \mathrm{CD}_{3} \mathrm{OD}\right)$

Chart 2. ${ }^{1} \mathrm{H}$ NMR Spectrum of aplaminal (1; $270 \mathrm{MHz}$, acetone- $d_{6}$ )

Chart 3. ${ }^{13} \mathrm{C}$ NMR Spectrum of aplaminal $\left(1 ; 151 \mathrm{MHz}, \mathrm{CD}_{3} \mathrm{OD}\right)$

Chart 4. ${ }^{1} \mathrm{H}-{ }^{1} \mathrm{H}$ COSY Spectrum of aplaminal $\left(1 ; 270 \mathrm{MHz}, \mathrm{CD}_{3} \mathrm{OD}\right)$

Chart 5. HMQC Spectrum of aplaminal (1; $\left.600 \mathrm{MHz}, \mathrm{CD}_{3} \mathrm{OD}\right)$

Chart 6. HMBC Spectrum of aplaminal $\left(\mathbf{1} ; 600 \mathrm{MHz}, \mathrm{CD}_{3} \mathrm{OD}\right)$ 


\section{Experimental Procedures}

Material. The sea hare Aplysia kurodai was collected at the reef of Azurihama, Mie, Japan.

Extraction and isolation. Approximately $18 \mathrm{~kg}$ (wet weight) of sea hare was extracted with methanol (36 L) for 1 week. The extract was filtered, and the filtrate was concentrated. The residue was partitioned between ethyl acetate $(3 \times 1 \mathrm{~L})$ and water $(1 \mathrm{~L})$. The ethyl acetate layer was washed with water $(500 \mathrm{~mL})$ and concentrated. The residue (21.9 g) was partitioned between $90 \%$ methanol $(1 \mathrm{~L})$ and hexane $(2 \times 1 \mathrm{~L})$. The $90 \%$ methanol layer was concentrated and partitioned between $60 \%$ methanol $(1 \mathrm{~L})$ and dichloromethane $(2 \times 1 \mathrm{~L})$. The dichloromethane layer was concentrated. The residue (11.8 g) was loaded on a silica gel column (200 g) and eluted with benzene-ethyl acetate = 1:1 $\rightarrow$ ethyl acetate $\rightarrow$ ethyl acetate-methanol $=4: 1 \rightarrow 1: 1 \rightarrow$ methanol $(1.2 \mathrm{~L}$ each). The concentrated fraction $(0.7 \mathrm{~g})$ eluted with ethyl acetate-methanol $=1: 1$ was loaded on an aluminum oxide column $(0.7 \mathrm{~g})$ and eluted with ethyl acetate $\rightarrow$ ethyl acetate-methanol $=19: 1 \rightarrow 9: 1$. The concentrated fraction (9.7 mg) eluted with ethyl acetate - methanol $=19: 1$ was chromatographed by reversed-phase HPLC [1. Develosil ODS-HG-5, ф $20 \times 250 \mathrm{~mm}$, acetonitrile-0.02 M ammonium acetate $=65: 35,5 \mathrm{~mL} / \mathrm{min}, \mathrm{t}_{\mathrm{R}}=5 \mathrm{~min} ; 2$. Develosil ODS-HG-5, $\phi 20 \times 250 \mathrm{~mm}$, methanol-water $=$ $50: 50,5 \mathrm{~mL} / \mathrm{min}, \mathrm{t}_{\mathrm{R}}=21 \mathrm{~min}$ ] to give $\mathbf{1}(2.0 \mathrm{mg}, 0.00001 \%$ based on wet $\mathrm{wt})$.

${ }^{1}$ H NMR Data for aplaminal (1; 270 MHz, acetone- $\left.\boldsymbol{d}_{6}\right) \delta 7.76$ (d, $\left.J=9.1 \mathrm{~Hz}, 2 \mathrm{H}\right), 6.85$ (d, $J=9.1$ Hz, 2H), 6.62 (br s, 1H), 4.26 (ddd, $J=1.4,5.7,9.2 \mathrm{~Hz}, 1 \mathrm{H}$ ), 3.85-3.75 (m, 1H), 3.79 (s, 3H), 3.78 (s, 3H), 3.66 (m, 1H), 3.36 (d, $J=9.2 \mathrm{~Hz}, 1 \mathrm{H}), 3.23$ (m, 1H), 2.46 (s, 3H). 


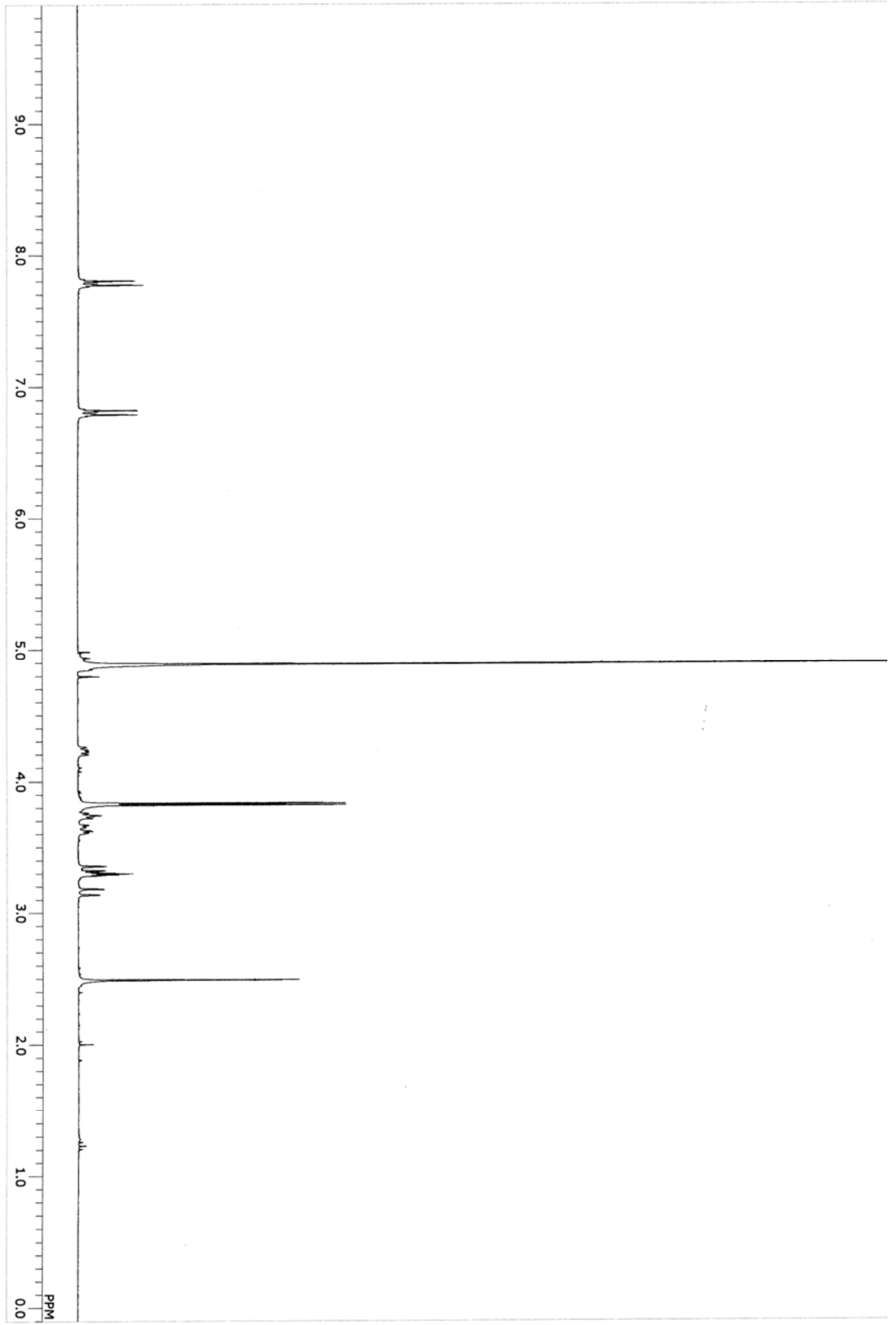

Chart 1. ${ }^{1} \mathrm{H}$ NMR spectrum of $\mathbf{1}$ [270 MHz, $\mathrm{CD}_{3} \mathrm{OD}$ ]. 


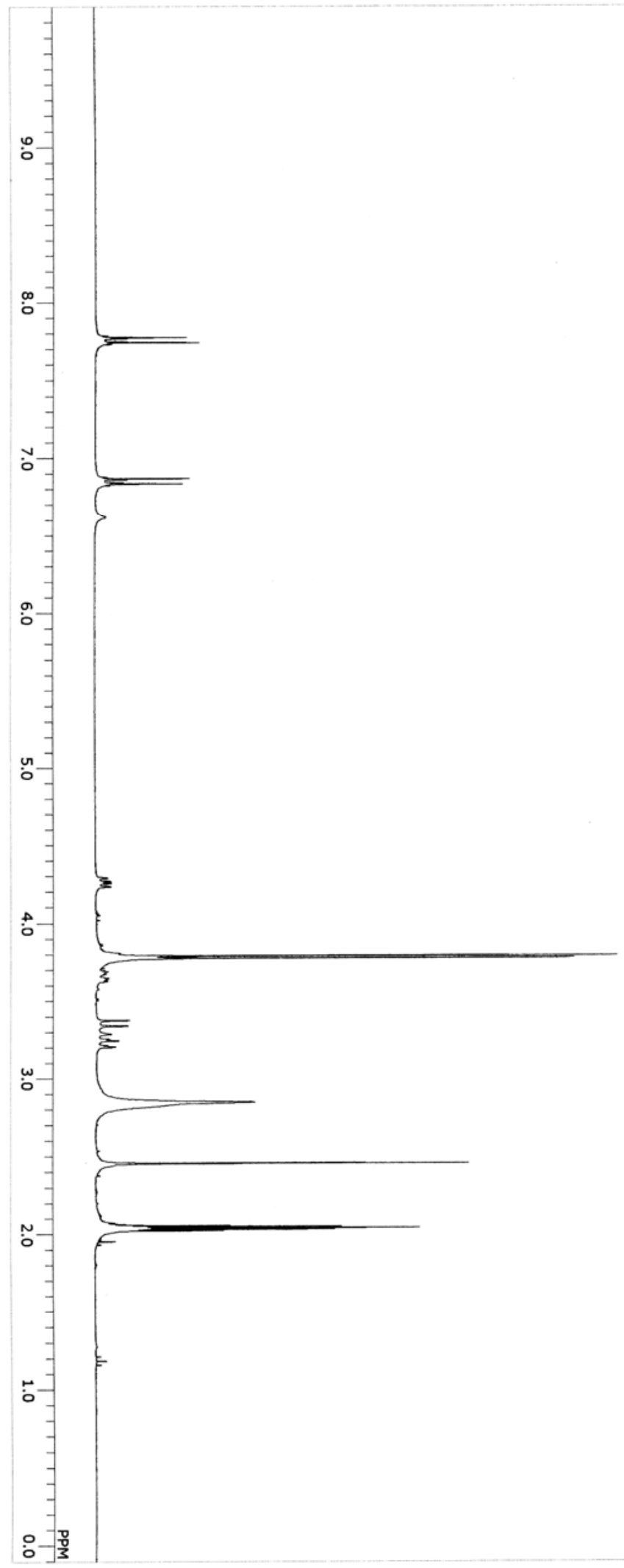

Chart 2. ${ }^{1} \mathrm{H}$ NMR spectrum of $\mathbf{1}$ [270 MHz, acetone- $d_{6}$ ]. 


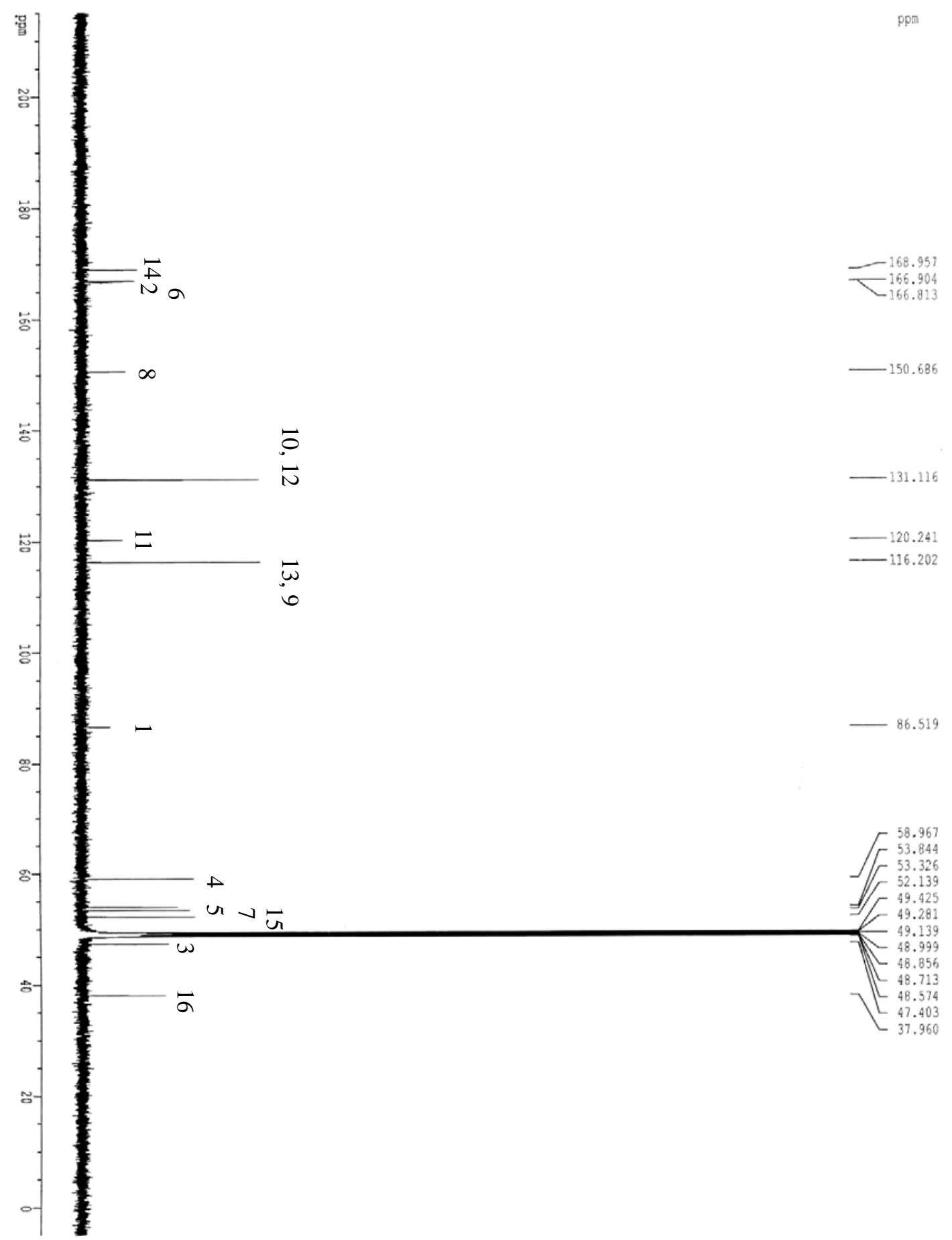

Chart 3. ${ }^{13} \mathrm{C}$ NMR spectrum of $\mathbf{1}$ [151 MHz, $\left.\mathrm{CD}_{3} \mathrm{OD}\right]$. 


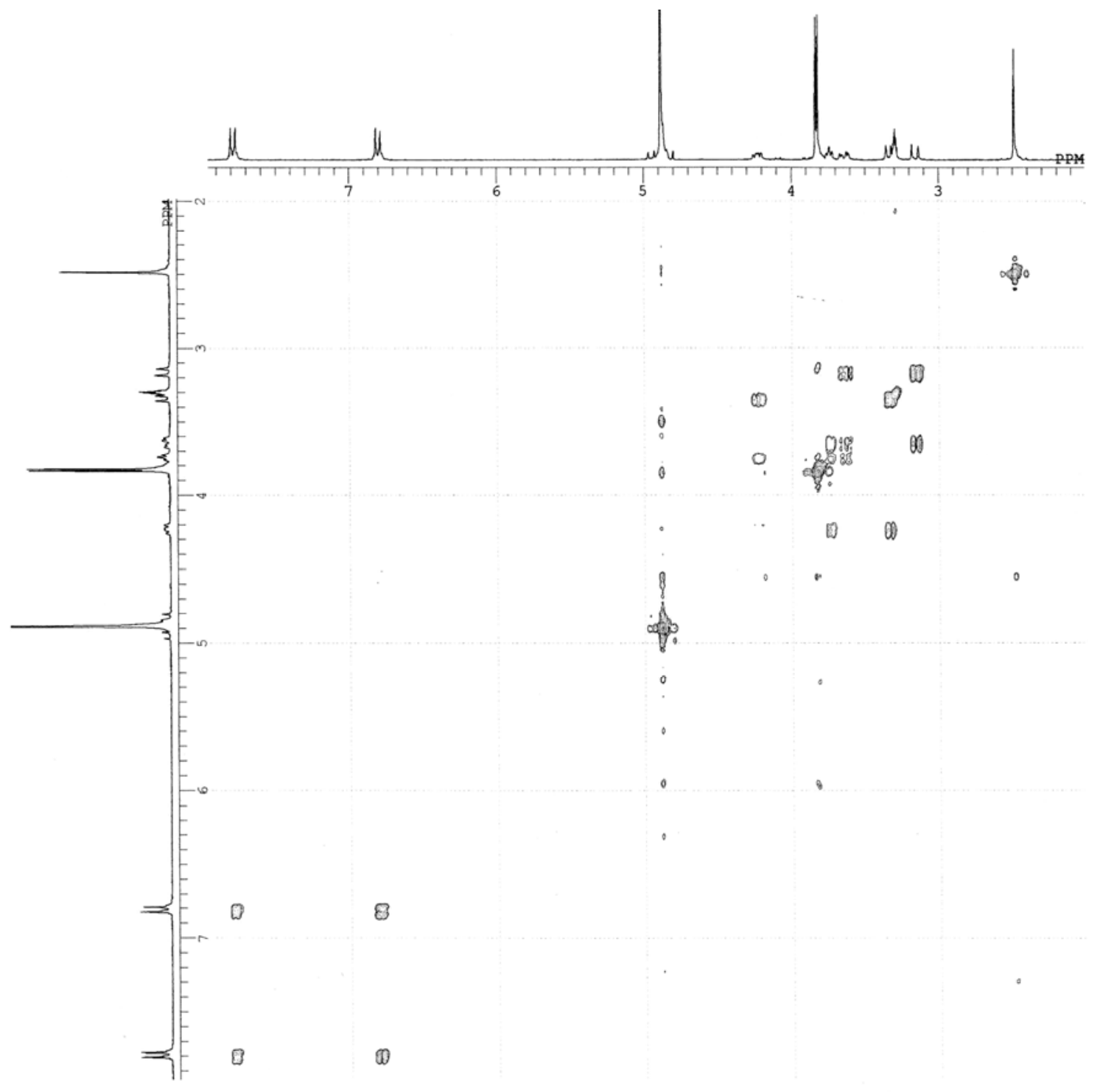

Chart 4. ${ }^{1} \mathrm{H}^{1}{ }^{1} \mathrm{H}$ COSY spectrum of $\mathbf{1}\left[270 \mathrm{MHz}, \mathrm{CD}_{3} \mathrm{OD}\right]$. 


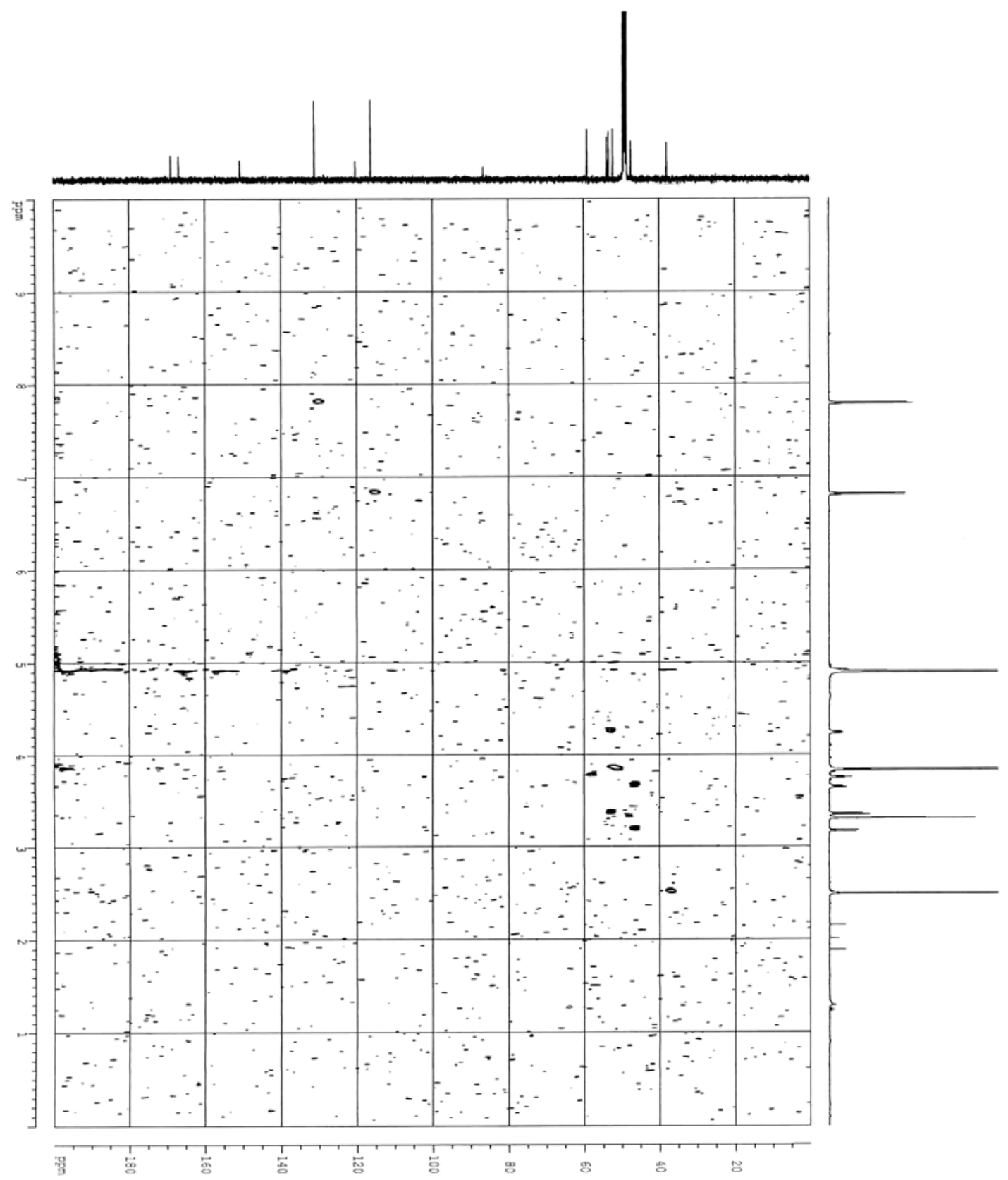

Chart 5. HMQC spectrum of 1 [600 MHz, $\left.\mathrm{CD}_{3} \mathrm{OD}\right]$. 


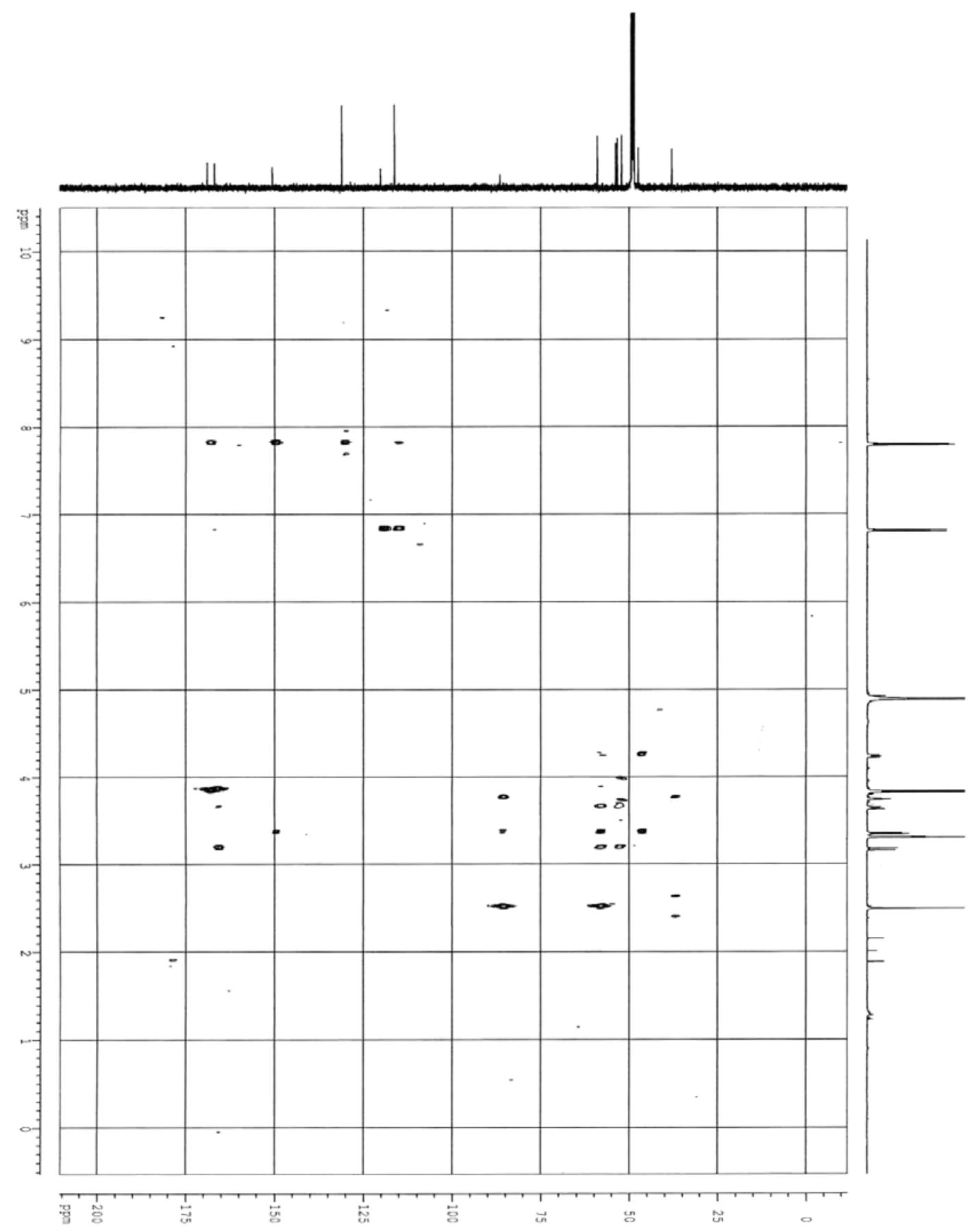

Chart 6. $\mathrm{HMBC}$ spectrum of $\mathbf{1}$ [600 MHz, $\mathrm{CD}_{3} \mathrm{OD}$ ]. 